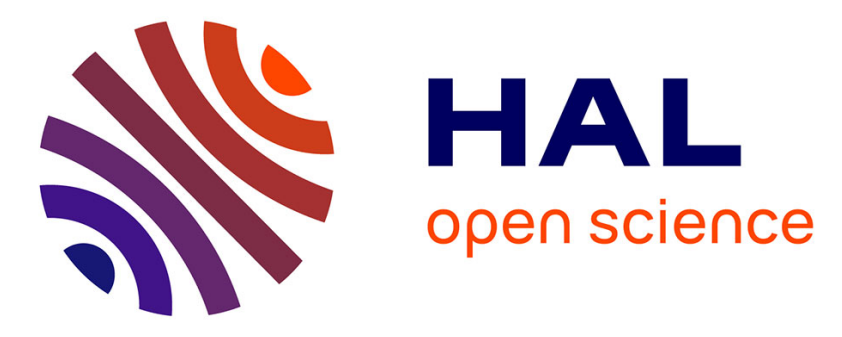

\title{
Mesoporous silicon nanoparticles for targeted two-photon theranostics of prostate cancer
}

Arnaud Chaix, Khaled El Cheikh, Elise Bouffard, Marie Maynadier, Dina Aggad, Vanja Stojanovic, Nikola Knezevic, Marcel Garcia, Alain Morère, Philippe Maillard, et al.

\section{To cite this version:}

Arnaud Chaix, Khaled El Cheikh, Elise Bouffard, Marie Maynadier, Dina Aggad, et al.. Mesoporous silicon nanoparticles for targeted two-photon theranostics of prostate cancer. Journal of materials chemistry B, 2016, 4 (21), pp.3639-3642. 10.1039/C6TB00690F . hal-03125636

\section{HAL Id: hal-03125636 https://hal.science/hal-03125636}

Submitted on 4 Feb 2021

HAL is a multi-disciplinary open access archive for the deposit and dissemination of scientific research documents, whether they are published or not. The documents may come from teaching and research institutions in France or abroad, or from public or private research centers.
L'archive ouverte pluridisciplinaire HAL, est destinée au dépôt et à la diffusion de documents scientifiques de niveau recherche, publiés ou non, émanant des établissements d'enseignement et de recherche français ou étrangers, des laboratoires publics ou privés. 


\section{Mesoporous silicon nanoparticles for targeted two-photon theranostic of prostate cancer}

\author{
Arnaud Chaix, ${ }^{a}$ Khaled El Cheikh, ${ }^{\mathrm{b}}$ Elise Bouffard, ${ }^{\mathrm{b}}$ Marie \\ Maynadier, ${ }^{\mathrm{c}}$ Dina Aggad, ${ }^{\mathrm{b}}$ Vanja Stonajovic, ${ }^{\mathrm{b}}$ Nikola \\ Knezevic, ${ }^{a}$ Marcel Garcia, ${ }^{b}$ Philippe Maillard, ${ }^{\mathrm{d}}$ Alain \\ Morère, ${ }^{\mathrm{b}}$ Magali Gary-Bobo, ${ }^{\mathrm{b}}$ Laurence Raehm, ${ }^{\mathrm{a}}$ \\ Sébastien Richeter, ${ }^{a}$ Jean-Olivier Durand ${ }^{a}$ and Frédérique \\ Cunin $^{a}$
}

A novel non toxic porous silicon nanoparticle grafted with a mannose-6-phosphate analogue and applicable in 2-photon imaging and photodynamic therapy was specifically designed for targeting prostate cancer cells.

Prostate carcinoma is a malignant tumor which represents the second leading cause of men death after lung cancer. ${ }^{1}$ The onset of prostate cancer begins as a slow growing and indolent lesions which may degenerate into aggressive and metastatic tumors. Methods for prostate cancer treatment currently include prostatectomy, chemotherapy, hormonal therapy and radiotherapy. ${ }^{2}$ However, the persistent limitations for such treatments include their low specificity to the tumor, causing irreversible side effects, and the risk of developing resistance to treatment. A promising approach to increase the intratumoral concentration of an anticancer agent and to limit the toxic effects in healthy tissue is to target cell membrane receptors over-expressed in cancer cells. ${ }^{3}$ Moreover minimally invasive therapies such as photodynamic therapy (PDT), currently applied in clinics, can treat the tumor area in a very localized way, ${ }^{4}$ by exposure to light irradiation. PDT is indicated for the treatment of small size solid tumors (such as prostate tumor at an early stage of detection) where heavy surgery or chemotherapy is not justified. ${ }^{5}$ The development of therapeutic systems combining the use of nanoparticles with targeting capabilities and PDT, which uses localized irradiation, would be highly beneficial for the treatment of prostate cancer. Porous silicon nanoparticles (pSiNPs) are attractive materials as drug carriers as they are biodegradable and nontoxic invivo. ${ }^{6}$ They display intrinsic photoluminescence under near infrared 2-photon excitation, in the spectral window suitable for medical applications. ${ }^{7}$ In a previous article, we described a system composed of pSiNP grafted with porphyrin and carbohydrate derivatives for efficient targeting of MCF-7 breast cancer cells. pSiNP functionalized with porphyrin upon excitation with OPE and TPE (one photon and two photon excitation respectively) functioned by two different excitation mechanisms. ${ }^{8}$ Porphyrin was directly excited in the visible spectral region under OPE while it was indirectly excited by near infrared (NIR) irradiation through TPE by an energy transfer mechanism from the pSiNP. Furthermore, it is described in the literature that the prostate specific membrane antigen (PSMA), the most prevalent prostate cancer cell biomarker, is easily targeted with peptides $^{9}$, aptamers ${ }^{10}, 11$ and antibodies ${ }^{12}$. Recently, the overexpression of the cation-independent mannose-6-phosphate receptor (M6PR) was demonstrated in prostate cancer cell lines and tissues. ${ }^{13}$ M6PR was identified both as an alternative to PSMA biomarker for diagnosis and as a target for treatment purposes. One of the main functions of this receptor is to recognize M6P-containing enzymes at the cell membrane and to route them to the lysosomes. ${ }^{14}$ In this work, we describe a new type of nanovector which are pSiNP functionalized with a moiety analogous to mannose-6-phosphate: the mannose 6-carboxylate (M6C), specifically prepared for an active targeting of M6PR. ${ }^{13} \mathrm{An}$ analogue of the M6P is more appropriate for the targeting of M6PR than the M6P group itself because phosphatases, and especially prostatic acid phosphatases, that selectively hydrolyze phosphomonoester, are over produced in prostate and are serum prognostic marker for patients with prostate cancer. ${ }^{15}$ The targeting pSiNPs also carry porphyrins, covalently attached on their surface, for 2-photon imaging and targeted PDT of prostate cancer cells (LNCaP).

The pSiNP were prepared according to the established procedure by electrochemical etching of boron doped silicon wafer in an ethanolic hydrofluoric acid (HF) electrolyte, then electropolished in order to remove the porous silicon layer from the substrate. ${ }^{8,} 16$ Afterwards the pSiNPs were generated by ultrasonication of the porous film for $16 \mathrm{~h}$ and centrifuged twice to separate the microparticles from the nanoparticles (more details of the pSiNP preparation are given in the supporting information). The pSiNPs were then characterized by Transmission Electron Microscopy (TEM) which revealed the mesoporous structure of the nanoparticles with size between 100-250 nm and pore diameter of 15-25 nm (Fig. S1a, b, ESI). Nitrogen adsorption and desorption analysis confirmed the mesoporous texture of the pSiNPs with $19.5 \mathrm{~nm}$ mean pore diameter and a high specific surface area of $493 \mathrm{~m}^{2} / \mathrm{g}$ (Fig. S2a, ESI). Dynamic light scattering (DLS) indicated an average size of the pSiNPs at 164 $\mathrm{nm}$ with a polydispersity of 0.22 consistent with TEM images (Fig. S5, ESI). Furthermore, X-ray diffraction (XRD) pattern showed the presence of a crystalline structure for the pSiNPs (Fig. S2b, ESI). 
a
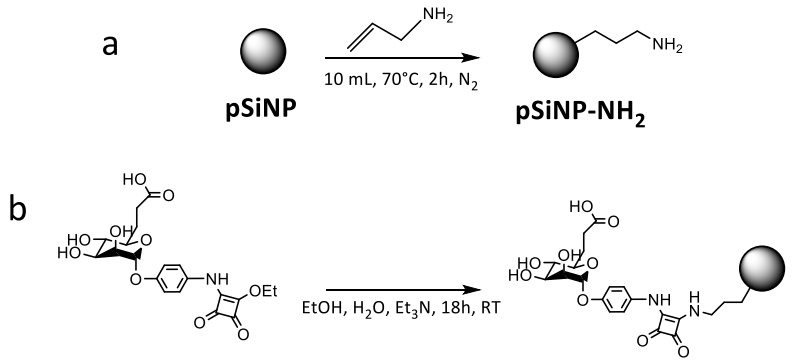

pSiNP-M6C
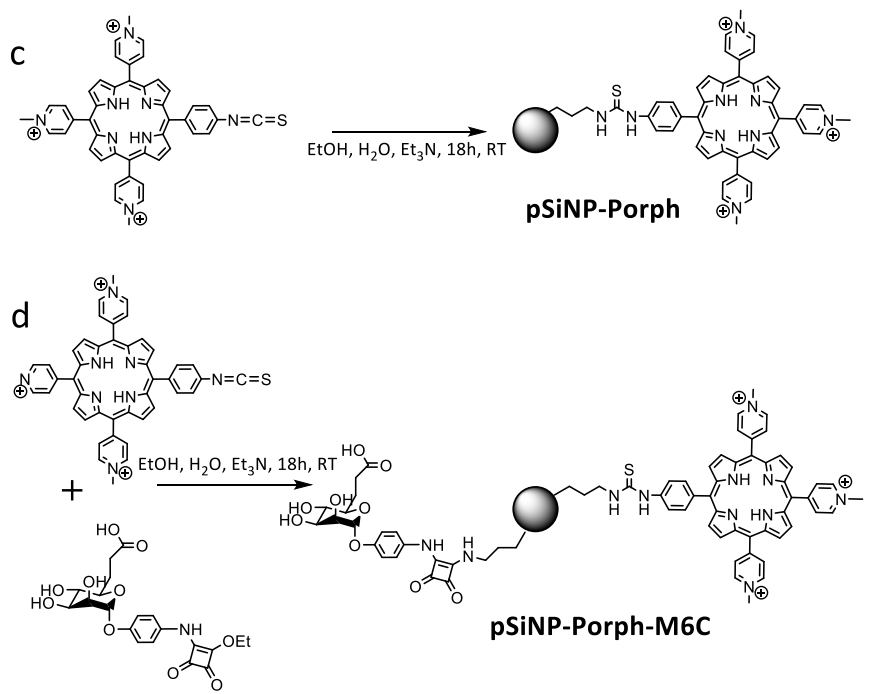

Figure 1. Reaction scheme for a) the hydrosilylation of allylamine with pSiNP, b) the coupling of $\mathrm{M} 6 \mathrm{C}$ with pSiNP-NH,$c$ ) the coupling of the porphyrin with pSiNP-NH , and d) the simultaneous coupling of $\mathrm{M} 6 \mathrm{C}$, and the porphyrin with pSiNP-NH

Three pSiNP-based formulations were prepared and their targeting and photodynamic efficiencies were tested on LNCaP prostate cancer cells. The three formulations are pSiNP-M6C, pSiNPPorph, and pSiNP-Porph-M6C, which correspond respectively to M6C-grafted pSiNP, porphyrin (5-(4-iso-thiocyanatophenyl)10,15,20-tris(1-methyl-4-pyridinio)porphyrin trichloride)-grafted pSiNP and pSiNP grafted with both M6C and the porphyrin (Fig. 1). The porphyrin and $\mathrm{M} 6 \mathrm{C}$ were prepared according to procedures described in the ESI part. Prior to the attachment of M6C and porphyrin, allylamine was grafted to the pSiNP via hydrosilylation. Immediately after, the pSiNP- $\mathrm{NH}_{2}$ was allowed to react with the isothiocyanate of the porphyrin and with $\mathrm{M} 6 \mathrm{C}$. Here the M6C derivative was functionalized at its $\alpha$-anomeric position with a phenyl squarate spacer arm available for selective covalent reaction with the amino functions of the pSiNP-NH . UV-vis absorbance measurements and diffuse reflectance infrared Fourier transform (DRIFT) spectroscopy confirmed the presence of the porphyrin and of the M6C onto the functionalized nanoparticles surface (Fig S3-S4, ESI). Measurements of the hydrodynamic diameter of the nanoparticles formulations by DLS and of their surface charge (zeta potential) also indicate successful functionalization of the nanoparticles in the different formulations (Fig. S5-S6, ESI). The mass loading of porphyrin and M6C in the pSiNP was determined using UVvis spectroscopy (Fig. S6, ESI). The amount of grafted M6C was determined by spectrophotometry by reaction with resorcinol (Table
S1, ESI). Moreover, a cytotoxicity study with increasing concentrations (from 20 to $160 \mu \mathrm{g} / \mathrm{mL}$ ) of each formulation incubated with LNCaP cells indicated that no significant toxicity was observed after $72 \mathrm{~h}$ incubation in dark (Fig. S7).
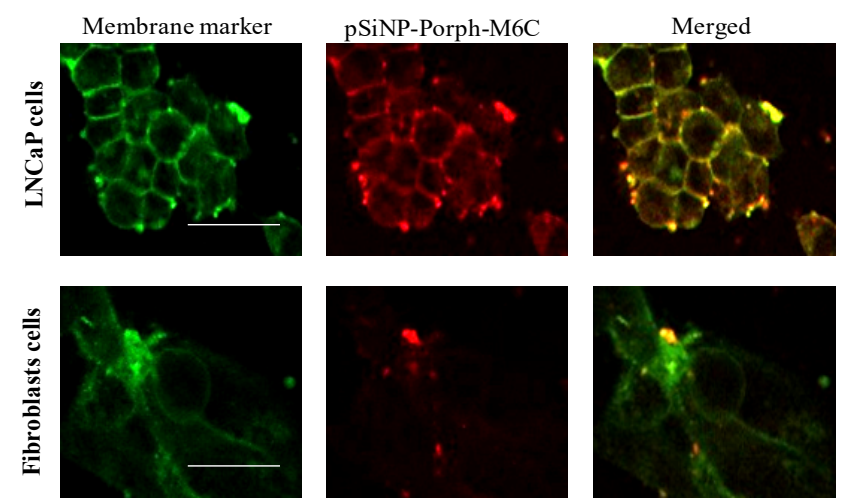

Figure 2. Confocal microscopy imaging on prostate cancer cells (LNCaP) and normal fibroblasts. Cells were incubated $5 \mathrm{~h}$ with $80 \mu \mathrm{g} \cdot \mathrm{mL}^{-1} \mathrm{pSiNP}$-Porph$\mathrm{M} 6 \mathrm{C}$ and co-stained with a membrane marker (cell mask). Cell membranes were visualized in green, and pSiNP-Porph-M6C was visualized at $800 \mathrm{~nm}$. Scale bar of $10 \mu \mathrm{m}$.

Cellular internalization of the functionalized nanoparticles was analyzed by two-photon fluorescence microscopy on LNCaP prostate cancer cells and on normal fibroblasts. LNCaP cells overexpress M6P receptor (M6PR), which is not the case for fibroblasts. ${ }^{13} \mathrm{LNCaP}$ and fibroblasts cells were incubated for 5 hours at a concentration of 80 $\mu \mathrm{g} . \mathrm{mL}^{-1}$ with pSiNP-Porph-M6C. Both cell lines were rinsed before being excited by means of a Carl Zeiss pulsed laser $\left(\lambda_{\text {exc }}=800 \mathrm{~nm}\right.$ ) and imaged. The fluorescence images in figure 2 show an important red fluorescence from the pSiNP-Porph-M6C when incubated with LNCaP cells. Such red fluorescence is attributed to the porphyrin emission after 2-photon excitation of the pSiNP and energy transfer to the porphyrin. This mechanism of indirect 2-photon excitation of the porphyrin was previously demonstrated by our group. ${ }^{8}$ The pSiNP-Porph-M6C appear to be localized at the cell membrane and also internalized. In comparison, much lower fluorescence was observed from the nanoparticles when incubated with fibroblasts. This difference between LNCaP cells and fibroblasts is attributed to the higher expression level of M6PR in LNCaP, and to the higher endocytosis capacity of cancer cells in comparison with normal ones (Fig. 2). Indeed, nanoparticles of optimized size (30-300 nm) tend to passively accumulate in tumors due to EPR effect, while surface chemical modification allows to significantly improve the cellular uptake of the nanoparticles by active targeting. Here the cellular endocytosis of the nanoparticles is mediated by an active mechanism involving the Mannose-6-phosphate receptor. ${ }^{13}$

The capacity of the functionalized nanoparticles to generate oxidative stress under 2PE irradiation was then analyzed by Dichlorofluorescein diacetate assay on LNCaP prostate cancer cells. LNCaP cells were incubated for 5 hours with pSiNP, pSiNP-porph, pSiNP-M6C and pSiNP-Porph-M6C at a concentration of $80 \mu \mathrm{g} \cdot \mathrm{mL}^{-1}$ and then exposed to $20 \mu \mathrm{M} \mathrm{2}$ ', 7'-dichlorofluorescein diacetate for 45 minutes. Cells were rinsed and imaged before and after laser irradiation at $800 \mathrm{~nm}$ for $1.57 \mathrm{~s}$. Figure S8 (ESI) shows increase in fluorescence due to ROS production in cells treated with pSiNP- 
porph, pSiNP-M6C and pSiNP-Porph-M6C after laser irradiation. The oxidative stress was observed to be higher with pSiNP-porph and pSiNP-Porph-M6C nanoparticles, and the highest oxidative stress was induced by pSiNP-Porph-M6C nanoparticles. No difference in ROS production was observed with pSiNP nanoparticles before and after irradiation.

In addition, In vitro PDT under two photon excitation (TPE) on LNCaP cells was performed (Fig. 3). LNCaP cells were incubated for 5 $\mathrm{h}$ with pSiNP, pSiNP-M6C, pSiNP-Porph, and pSiNP-Porph-M6C at a concentration of $80 \mu \mathrm{g} / \mathrm{mL}$. Two-photon irradiation was achieved using a Carl Zeiss confocal two-photon microscope (maximal power, laser input power $3 \mathrm{~W}$ ). Cells were irradiated by 3 laser pulses of 1.57 $\mathrm{s}$ each at an irradiation wavelength of $800 \mathrm{~nm}$, (using the 10-fold magnification/objective 0.3 EC Plan-Neofluar). Two days after irradiation, the percentage of living cells was determined by MTS assay. The pSiNP induced a significant cell death of $16 \%$ confirming the capacity of porous silicon to generate ${ }^{1} \mathrm{O}_{2}$ and ROS under TPE. ${ }^{8}$ In addition, the use of pSiNP-M6C drastically enhanced the cell death (44\%) showing the role of the M6C in the pSiNP cell targeting. Comparable cell death levels were induced using pSiNP-Porph (40\%) and pSiNP-Porph-M6C (50\%). When compared to the activity of pSiNP, the higher photodynamic efficiency of pSiNP-Porph can be ascribed to the enhanced passive endocytosis of the pSiNP-Porph due to electrostatic interactions between the cationic pSiNP-Porph and the anionic cell membrane ${ }^{17}$; in contrast active endocytosis of pSiNP-M6C is M6PR dependent. In the case of pSiNP-Porph-M6C, the phototoxicity increase could be attributed to both, the electrostatic interactions and the efficiency of M6C to target M6PR.The phototoxicity efficiency is also related to the efficiency of the energy transfer from pSiNP to the porphyrin upon TPE, as previously demonstrated by our group. ${ }^{8}$ The low increase of toxicity of pSiNPPorph-M6C compared to pSiNP-Porph is certainly due to the deactivation of the pSiNP excited state by the aromatic phenyl squarate moiety present on the M6C species. Finally, this study reveals that in the case of pSiNP-based nanotherapeutics the photodynamic efficiency and targeting of M6PR under TPE is high even without the covalently attached photosensitizers. These results showcase the benefits of using M6C-functionalized pSiNP for TPE and the M6PR as a target for prostate cancer therapy.

In conclusion, a mannose 6-phosphate analogue was prepared and successfully grafted on the surface of pSiNP for in vitro targeted TPE-PDT of prostate cancer cells. The M6C grafting allowed a higher uptake of the nanoconstructs by cancer cells than by normal ones, and improved the photodynamic efficiency. We showed that the

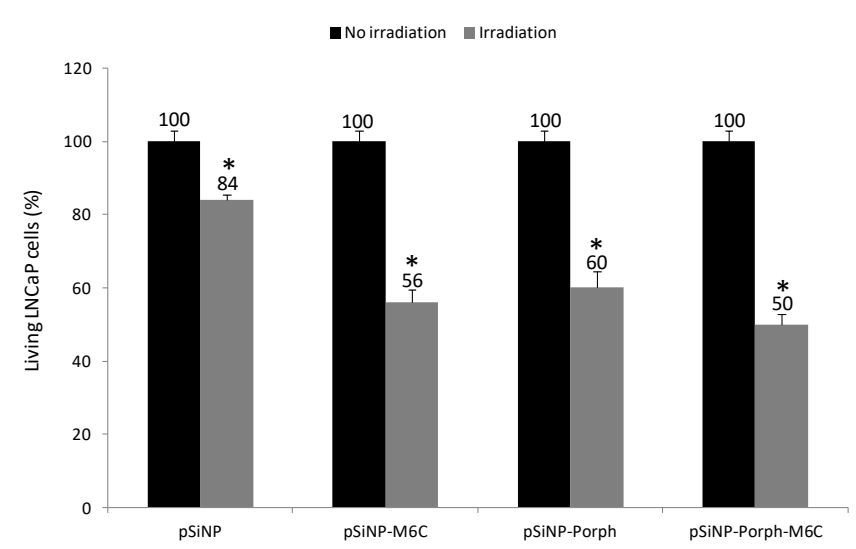

Figure 3. In vitro photodynamic effect of pSiNP, pSiNP-M6C, pSiNP-Porph and pSiNP-Porph-M6C, on LNCaP cells. The cells were incubated $5 \mathrm{~h}$ with 80 $\mu \mathrm{g} . \mathrm{mL}^{-1}$. The percents of living cells were obtained after TPE irradiation (800 $\mathrm{nm}, 3$ scans of $1.57 \mathrm{~s}$ ). Bar graphs represent means of triplicates \pm standard deviations. Statistical analysis was performed using the Student's test. *: $p$ $<0.05$ was considered to be statistically different from control values.

M6PR is a useful receptor for devising targeting nanomedicines, particularly for prostate cancer targeting.

\section{Acknowledgements}

The ANR (Agence Nationale pour la Recherche, programme Blanc inter I SIMI 10, edition 2012), the Carnot Institut (pole Chimie Balard) and LabEx CheMISyst (2012-2015) are gratefully acknowledged for fundings. The authors thank T. Cacciaguerra for TEM imaging.

\section{References}

1. A. Chiarodo, Cancer Research, 1991, 51, 2498-2505.

2. D. F. Penson, M. Rossignol, A. O. Sartor, P. T. Scardino and L. L. Abenhaim, Urology, 2008, 72, 3-11.

3. F. Schmitt and L. Juillerat-Jeanneret, Anti-Cancer Agent Me, 2012, 12, 500-525.

4. a. Z. G. R. K. Pandey, The porphyrin Hanbook, K. M. Kadish and R. Guilard. Eds. Vol. 6, 43, 2000, 2000.

5. C. A. Robertson, D. H. Evans, H. Abrahamse. J Photochem Photobiol B. 2009, 96(1), 1-8.

6. J. H. Park, L. Gu, G. von Maltzahn, E. Ruoslahti, S. N. Bhatia and M. J. Sailor, Nat Mater, 2009, 8, 331-336.

7. M. N. E. R. W. Waynant, Electrooptics Hanbook, McGrawHill, New York, 1993, ch.24., 2000.

8. E. Secret, M. Maynadier, A. Gallud, A. Chaix, E. Bouffard, M. Gary-Bobo, N. Marcotte, O. Mongin, K. El Cheikh, V. Hugues, M. Auffan, C. Frochot, A. Morere, P. Maillard, M. Blanchard-Desce, M. J. Sailor, M. Garcia, J. O. Durand and F. Cunin, Adv Mater, 2014, 26, 7643-7648.

9. C. L. Esposito, L. Cerchia, S. Catuogno, G. De Vita, J. P. Dassie, G. Santamaria, P. Swiderski, G. Condorelli, P. H. Giangrande and V. de Franciscis, Mol Ther, 2014, 22, 11511163.

10. O. C. Farokhzad, S. Y. Jon, A. Khademhosseini, T. N. T. Tran, D. A. LaVan and R. Langer, Cancer Research, 2004, 64, 7668-7672.

11. S. Dhar, F. X. Gu, R. Langer, O. C. Farokhzad and S. J. Lippard, P Natl Acad Sci USA, 2008, 105, 17356-17361. 
12. N. H. Bander, E. J. Trabulsi, L. Kostakoglu, D. Yao, S. Vallabhajosula, P. Smith-Jones, M. A. Joyce, M. Milowsky, D. M. Nanus and S. J. Goldsmith, J Urology, 2003, 170, 1717-1721.

13. O. Vaillant, K. El Cheikh, D. Warther, D. Brevet, M. Maynadier, E. Bouffard, F. Salgues, A. Jeanjean, P. Puche, C. Mazerolles, P. Maillard, O. Mongin, M. Blanchard-Desce, L. Raehm, X. Rebillard, J. O. Durand, M. Gary-Bobo, A. Morere and M. Garcia, Angew Chem Int Edit, 2015, 54, 5952-5956.

14. M. Gary-Bobo, P. Nirde, A. Jeanjean, A. Morere and M. Garcia, Curr Med Chem, 2007, 14, 2945-2953.

15. A. L. Taira, G. Merrick, K. Wallner and M. Dattoli, OncologyNy, 2007, 21, 1003-1010.

16. E. Secret, M. Maynadier, A. Gallud, M. Gary-Bobo, A. Chaix, E. Belamie, P. Maillard, M. J. Sailor, M. Garcia, J. O. Durand and F. Cunin, Chem Commun, 2013, 49, 4202-4204.

17. N. Oh and J. H. Park, Int J Nanomed, 2014, 9, 51-63. 